\title{
Comportamiento del empleo en actividades de ciencia, tecnología e innovación (ACTI) en el sector servicios - Colombia ${ }^{1}$
}

DOI: http://dx.doi.org/10.17981/econcuc.37.1.2016.05

\section{Julio Cesar Caro Moreno ${ }^{2}$}

\section{Resumen}

En el contexto actual, donde la innovación se ha convertido en una variable importante a la hora de tratar temas relacionados con el crecimiento económico, surge la necesidad de estudiar los procesos de innovación generados en el país, por lo que se identifican las variables que influyen directa e indirectamente en la determinación de procesos productivo y el empleo. Para este estudio, se analiza el comportamiento del empleo en actividades de ciencia, tecnología e innovación (ACTI) en el periodo del 2004 al 2011, en Colombia. Se abarca el sector servicios, no solo, por la tendencia mundial hacia la tercerización de la economía, sino también, por su creciente participación en el Producto Interno Bruto (PIB). En la primera, parte se plantearan los aspectos más relevantes con respecto al tema de innovación. Posteriormente, se realiza un análisis del comportamiento del empleo y la innovación en el sector servicios, basados en los datos suministrados por el Departamento Administrativo Nacional de Estadística (DANE) a través de las Encuestas de Desarrollo e Innovación Tecnológica para el Sector Servicios (EDITS), caracterizando la estructura del personal ocupado, en las ACTI del sector servicios.

Palabras clave: comportamiento laboral; actividades de ciencia y tecnología; innovación; sector servicios.

Recibido: 23.9.2015 Devuelto para revisión: 29.10.2015 Aceptado: 9.12.2015

\begin{abstract}
${ }^{1}$ Artículo científico derivado de la investigación "Innovación y cambio técnico en el sector Industrial y servicios en Colombia 2000-2010”, financiada por la Universidad Pedagógica y Tecnológica de Colombia (UPTC)- Boyacá, Colombia.

${ }^{2}$ Doctorando en Geografía. Universidad Pedagógica y Tecnológica de Colombia (UPTC)-Bogotá, Colombia. Magister en economía. Universidad Pedagógica y Tecnológica de Colombia (UPTC)- Boyacá, Colombia. Especialista en Finanzas. Economista. Universidad Pedagógica y Tecnológica de Colombia (UPTC).Docente tiempo completo de la Facultad de ciencias Económicas y administrativas adscrito al grupo de investigación SOECOL. Universidad Pedagógica y Tecnológica de Colombia (UPTC)-Bogotá, Colombia. julio.caro@uptc.edu.co
\end{abstract}

- The author; licensee Universidad de la Costa - CUC

Económicas CUC vol. 37 no. 1, pp. 95-122. Enero - Junio, 2016 Barranquilla. ISSN 0120-3932 Impreso, ISSN 2382-3860 Online 


\title{
Employment Performance in Activities of Science, Technology and Innovation (ACTI), in the Service Sector, in Colombia
}

\begin{abstract}
In the current context, where innovation has become an important variable in addressing issues related to economic growth, arises the need to study the innovation processes generated in the country, identifying the variables that influence directly and indirectly the determination of productive processes and employment. In this article, we analyze the behavior of employment in Science, Technology and Innovation Activities (STIA) from 2004 to 2011 in Colombia. It covers the services sector, not only to the global trend towards outsourcing, but also to its increasing participation in the Gross Domestic Product (GDP). First part, the most relevant aspects regarding the topic of innovation will be discussed. Subsequently, an analysis of the behavior of employment and innovation in the services sector is carried out based on the data provided by the National Administrative Department of Statistics (DANE) through the Development and Technological Innovation Surveys for the Services Sector (DTI) is conducted, characterizing the structure of the personnel employed in the STIAs of the services sector.
\end{abstract}

Keywords: work behavior; Science and technology activities; innovation; service sector.

\section{Introducción}

En el contexto actual donde la innovación se ha convertido en una variable importante a la hora de abordar temas relacionados con el crecimiento económico, surge la necesidad de estudiar de forma detallada los procesos de innovación generados en el país con el fin de identificar y analizar las variables que influyen directa e indirectamente en la determinación de los procesos de innovación y su impacto en la producción.

Para este estudio en particular se abarca el sector de servicios, debido no sólo a la tendencia mundial hacia la tercerización de la economía, sino también a su creciente participación en el Producto Interno Bruto (PIB) en la década del 2000 
en Colombia, con la que ha venido desplazando a los sectores tradicionalmente productivos.

En la primera parte de este artículo, se presenta una breve revisión teórica con respecto al tema de innovación; posteriormente, se describe el comportamiento del sector de servicios en la década del 2000 en Colombia con el fin de obtener una perspectiva de la influencia de este sector en la economía del país; seguidamente, se realiza un análisis del comportamiento de la innovación en el sector de servicios, teniendo como fundamento los datos suministrados por el Departamento Administrativo Nacional de Estadística (DANE) a través de las Encuestas de Desarrollo e Innovación Tecnológica para el Sector Servicios (EDITS), construyendo así una serie de indicadores que relacionan el comportamiento del personal ocupado con los cuales permiten analizar el impacto del empleo sobre la innovación del sector.

\section{La innovación en el sector de servicios y sus tipologias}

Una de las grandes discusiones a las que se ha enfrentado la teoría económica a través de los años ha sido la determinación de las fuentes de crecimiento y desa- rrollo dentro de una economía; la mayoría de los estudios en la actualidad concuerdan en atribuir a la innovación como un factor fundamental para el crecimiento y desarrollo en el actual contexto del modelo de globalización.

Las primeras contribuciones referentes a innovación son atribuidas a Schumpeter (1997), quien fue uno de los primeros en identificar a la innovación como fuente de crecimiento dentro de una serie de conceptos evolucionistas donde el aumento del producto era vinculado estrechamente con las innovaciones que aparecían en la producción ${ }^{3}$, a partir de esto, se vincularon otros factores al crecimiento económico, como la tecnología.

\section{Una aproximación al concepto de innovación en el sector de servicios}

El tema del estudio de la innovación en el sector servicios ha evolucionado a través del tiempo, para el ISEA (2008) esta evolución se ha desarrollado en cuatro etapas: indiferencia, subordinación o asimilación, autonomía o demarcación y síntesis.

\footnotetext{
${ }^{3}$ Anterior a esto, las teorías atribuían el crecimiento al ahorro y la acumulación de capital.
} 
En la etapa de indiferencia en la década de los ochenta, los servicios no se consideraban innovadores, por lo que no se encuentran estudios. Posteriormente, en los años noventa el tema va adquiriendo relevancia y se aplican conceptos relacionados con el sector manufacturero para analizar la innovación en el sector de servicios, denominada la etapa de la subordinación o asimilación.

Después se efectúan cambios en la concepción de la innovación en servicios en la etapa de autonomía o demarcación, donde se considera que este sector es totalmente diferente al sector manufacturero, por lo cual se requieren nuevas bases teóricas adaptadas a sus características propias. Finalmente, llega la etapa de sintesis donde los estudios y la realidad demuestran que la innovación en servicios tiene más similitudes que discrepancias con la innovación en el sector manufacturero y los estudios se empiezan a relacionar esto.

\section{Innovación desde la perspectiva del Manual de Oslo}

El Manual de Oslo de la Organización para la Cooperación y el Desarrollo Económico (OCDE y EUROSTAT, 1992) re- coge los conceptos, definiciones y la metodología utilizados para la elaboración de datos sobre innovación tecnológica. Este manual inicialmente fue enfocado hacia las industrias manufactureras, por lo que los conceptos de innovación tecnológica se fundamentan en la innovación de procesos y productos con muy escasa referencia a innovaciones no tecnológicas o de otros sectores.

\section{Según este manual (1992):}

"Una innovación tecnológica comprende nuevos productos y procesos, así como cambios tecnológicos significativos de productos y procesos. Una innovación ha sido implementada si ha sido introducida en el mercado (innovación de producto) o utilizada dentro del proceso de producción (innovación de proceso). Las innovaciones por tanto implican una serie de actividades científicas, tecnológicas, organizativas, financieras y comerciales".

No obstante, la distinción entre productos y procesos en el sector de servicios es poco clara, ya que la producción y el consumo ocurren simultáneamente, por lo cual agregan en su tercera edición la ampliación del concepto de producto donde se empieza a referir no sólo a bienes sino también a servicios, y agrega: 
"La actividad de innovación en este sector (servicios) es un proceso continuo, consistente en una serie de modificaciones que se introducen progresivamente en los productos y en los procesos, con una fase inicial, la cual consta de investigación, evaluación de ideas y confrontación comercial, lo que lleva a una modificación importante en los productos, procesos o métodos".

Así, se incorporan las siguientes definiciones de las clases de innovación:

- Innovación de producto en el sector de servicios. Son servicios cuyo uso intencionado o características de estructura difieren significativamente de los servicios ya producidos. Las innovaciones serán el resultado de inversiones substanciales en nuevo conocimiento, ya sea o no tecnológico.

- Innovación de proceso en el sector de servicios. Son formas nuevas, o mejoradas de manera significativa, de producir o proveer servicios. Por tanto, las innovaciones de proceso pueden ser innovaciones en los procesos de producción de los servicios o en los procesos de distribución o entrega (provisión).
- Innovación organizativa en el sector de servicios. Se refiere a la puesta en práctica de nuevos métodos de organización, como cambios en las prácticas de la empresa, organización del lugar de trabajo o en las relaciones externas de la empresa; además, dentro de esta innovación se encuentra la innovación de mercadotecnia, que implica la utilización de nuevos métodos de comercialización y nuevos comportamientos en el mercado, como por ejemplo, un nuevo segmento de mercado o la introducción en otra industria.

A pesar de que en la teoría están descritas estas innovaciones, en el sector de servicios se dificulta su identificación particular debido a que la mayoría de las innovaciones presentan un poco de cada uno de estos tipos; además, el carácter no almacenable e intangible de los servicios ha contribuido al desinterés por el estudio del tema, desviando este interés hacia los sectores tradicionalmente productivos. 
Tabla 1

Actividades de servicios según clasificación CIIU 3.A.C.

\begin{tabular}{|c|c|}
\hline CIIU Revisión 3 A.C. & Subsector de servicios \\
\hline División 40 & Suministro de electricidad, gas, vapor y agua caliente \\
\hline División 41 & Captación, depuración y distribución de agua \\
\hline División 50 & Comercio de vehículos automotores, combustibles y lubricantes \\
\hline División 51 & Comercio al por mayor, excepto el comercio de vehículos automotores \\
\hline División 52 & Comercio al por menor, excepto el comercio de vehículos automotores \\
\hline Grupos 551 y 552 & Hoteles y restaurantes \\
\hline Grupos 602 y 604 & Transporte de pasajeros por vía terrestre y de carga por carretera \\
\hline División 62 & Transporte por vía aérea \\
\hline Grupos $641 \mathrm{y} 642$ & Correos y telecomunicaciones \\
\hline Clase 6511 y 6512 & Actividades bancarias \\
\hline División 72 & Informática \\
\hline División 73 & Centros de investigación y desarrollo \\
\hline Grupo 805 & Educación superior privada \\
\hline Grupo 851 & Actividades relacionadas con la salud humana \\
\hline División 90 & Eliminación de desperdicios y aguas residuales, saneamiento y similares \\
\hline Grupo 921 & Actividades de cinematografía, radio y televisión y otras \\
\hline
\end{tabular}

Fuente: DANE-EDIT.

\section{Estructura y evolución del sector de servicios en Colombia}

El sector de servicios se dedica a actividades económicas que no se relacionan directamente con el proceso de producción. Están orientadas principalmente a la prestación de servicios necesarios para el funcionamiento de los demás sectores de la economía; es el caso de los servicios financieros, de educación, transporte, comercio, telecomunicaciones y construcción, entre otros. 
En las últimas dos décadas, el sector de servicios aumentó su participación en el Producto Interno Bruto (PIB), pasando de un $63 \%$ en la década de los noventa a un $65 \%$ en la década del dos mil, generando el $67 \%$ del empleo en la economía colombiana como lo revela el DANE en la Gran Encuesta Integrada de Hogares (GEIH), por esta razón las expectativas por parte del gobierno se dirigieron hacia este sector.

El sector de servicios en la década del 2000 ha tenido la mayor participación en el PIB con respecto a los demás sectores de la economía colombiana (tradicionalmente productivos), teniendo la mayor participación con un $64 \%$ en relación con los demás sectores, como se evidencia en el gráfico 1, donde el aporte del sector de servicios supera la suma del aporte de los demás sectores que componen la economía colombiana, convirtiéndose así en el sector promotor de la economía colombiana al seguir los parámetros de la economía mundial hacia la tercerización.

$\mathrm{Al}$ hacer un paralelo al inicio del periodo de análisis (año 2000) con el final del periodo (año 2012), se ve cómo el sector industrial y el agrícola han venido disminuyendo su participación cerca de un $2 \%$, mientras que el sector de construcción, explotación de minas y canteras y el sector de servicios han aumentado su participación cerca de un $1 \%$.

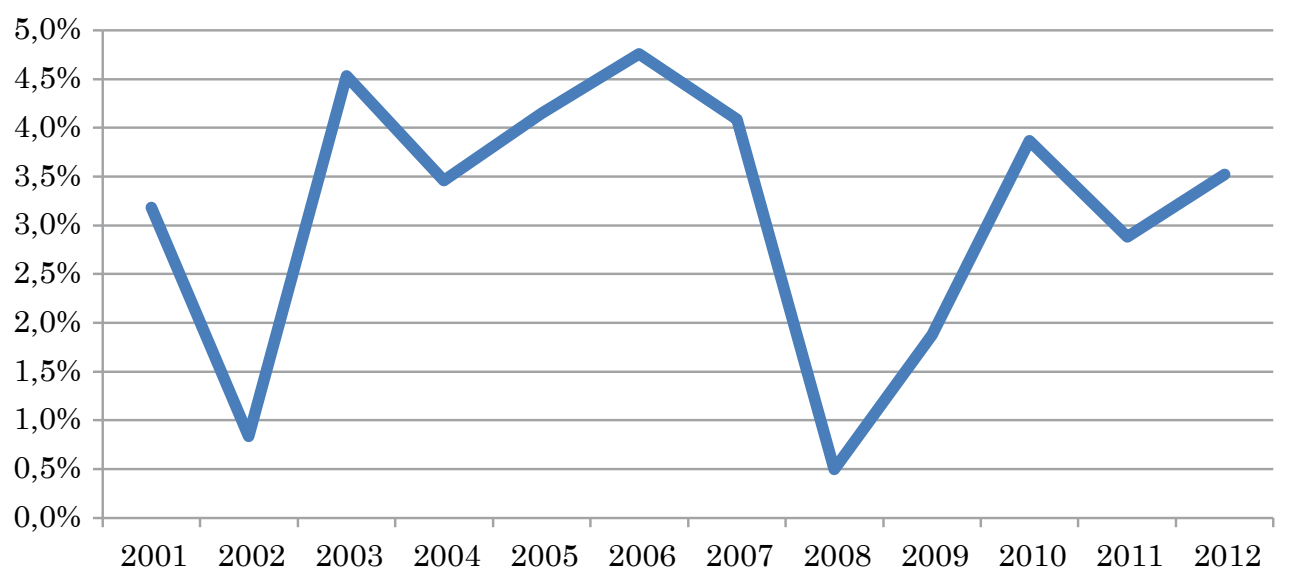

Gráfico 1. Crecimiento anual del sector de servicios para la década del 2000. Fuente: elaboración propia a partir del DANE $(2005,2007,2009,2011,2013)$. 


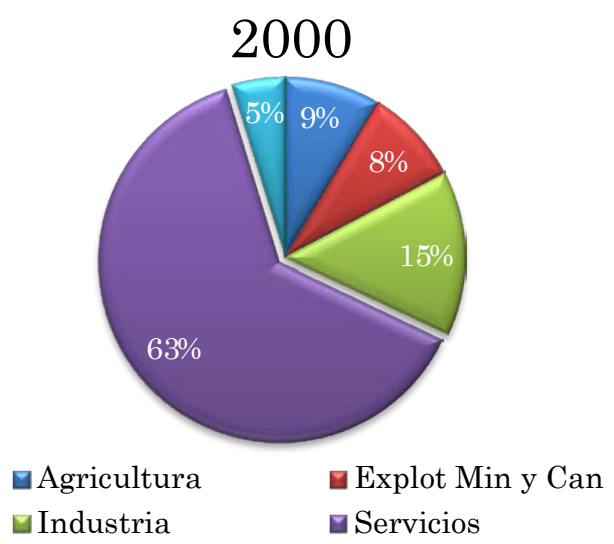

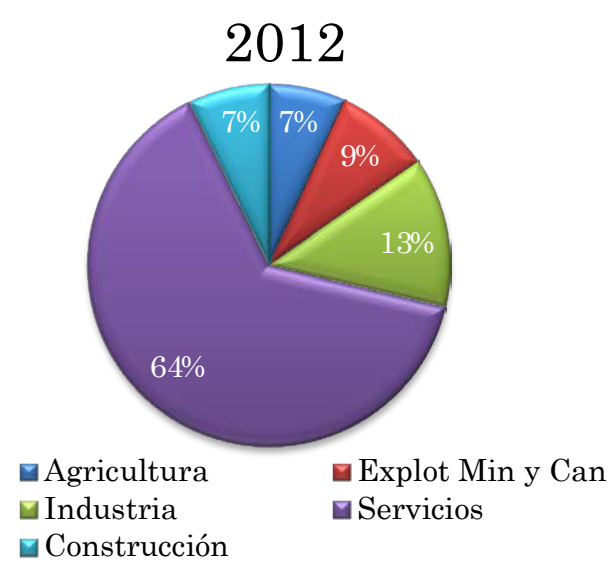

Gráfico 2. Participación por ramas de actividad económica en el 2000 y 2012. Fuente: elaboración propia a partir del DANE (2005, 2007, 2009, 2011, 2013).
Examinando el crecimiento en esta década, se observa cómo el sector de servicios, aun sin ser el que refleja el mayor crecimiento, es el sector que presenta un comportamiento más estable con respecto a los otros sectores; además, demostró cómo a pesar de los rezagos de la crisis económica mundial causada por la burbuja inmobiliaria en Estados Unidos y la crisis nacional causada por las captadoras ilegales de dinero (pirámides).

En 2008 y 2009 fue el sector con menos impacto con relación a los demás sectores que se vieron afectados. Como lo muestra el gráfico 3, el sector de servicios pasó de un crecimiento de $3.46 \%$ a uno de $2.09 \%$, disminuyendo en $1.37 \%$ en su peor momen- to, mientras que los sectores más afectados fueron el de la construcción, que pasó de un $5.28 \%$ a un $-0.10 \%$, registrando una caída de 5.38\%, y el de la industria, al tener una caída de $6.59 \%$ en 2008 y de $4.76 \%$ en 2009.

Para analizar a un poco más profundo el comportamiento del sector de servicios, se hace necesaria la desagregación del mismo, observando el comportamiento de cada uno de los subsectores que lo componen y teniendo en cuenta los factores que influyeron para el periodo 2000-2012 y su incidencia. El sector de servicios está compuesto por cinco subsectores los cuales son: comercio, transporte, almacenamiento y comunicaciones, estableci- 


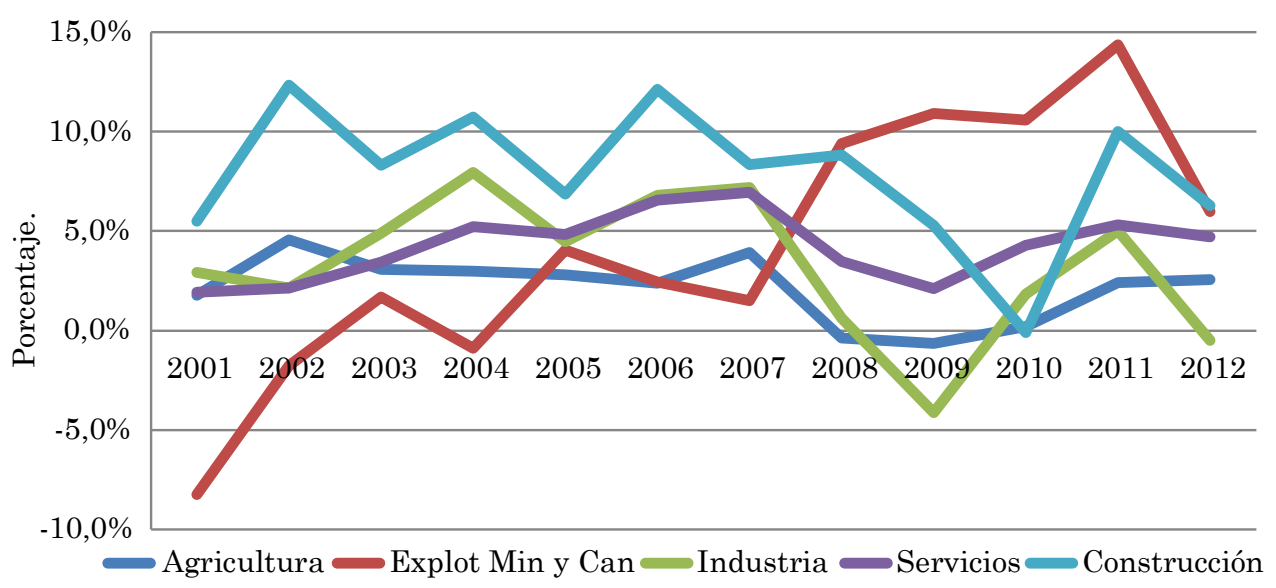

Gráfico 3. Crecimiento por ramas de actividad económica en la década del 2000. Fuente: elaboración propia a partir del DANE (2005, 2007, 2009, 2011, 2013).

mientos financieros, servicios sociales y comunales, y suministro de electricidad, gas y agua.

\section{Comportamientos de los subsectores que componen el sector de servicios}

$\mathrm{Al}$ analizar el sector de servicios de forma general, y al hacer una comparación de su composición en el año 2000 y en 2012 , se observa que su estructura fue la misma: hubo un incremento en la participación en los subsectores comercio y establecimientos financieros de un 1\% aproximadamente, mientras que los servicios sociales $y$ comunales disminuyeron su participación, pasando de un $29 \%$ en 2000 a un $26 \%$ en 2012.

También se observa que el subsector que más aportó al PIB fue el de establecimientos financieros, seguros, actividades inmobiliarias y servicios a las empresas, con un $33 \%$ aproximadamente, como se pone en evidencia en el gráfico 3, seguido del subsector de servicios sociales, personales y comunales, con un $28 \%$ aproximadamente; por otra parte, el subsector que aportó en menor medida al PIB fue el de suministro de electricidad, gas y agua, con un $7 \%$ aproximadamente. 


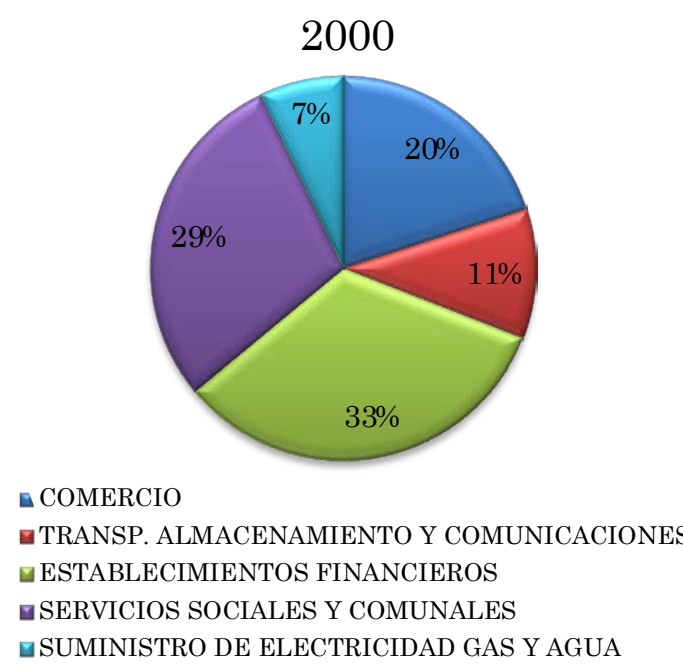

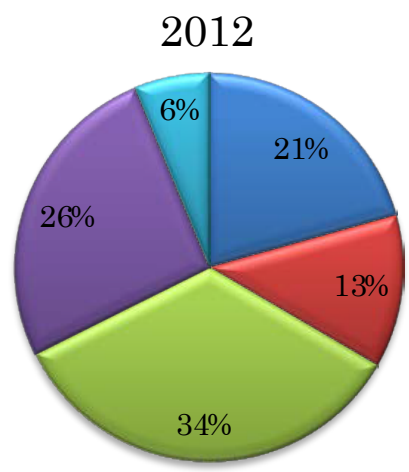

口COMERCIO

口TRANSP. ALMACENAMIENTO Y COMUNICACIONES $\square$ ESTABLECIMIENTOS FINANCIEROS $\square$ SERVICIOS SOCIALES Y COMUNALES $\square$ SUMINISTRO DE ELECTRICIDAD GAS Y AGUA

Gráfico 4. Composición del sector de servicios por subsectores en 2000 y 2012.

Fuente: elaboración propia a partir del DANE (2005, 2007, 2009, 2011, 2013).

Al desagregar el sector de servicios y obtener la participación de los subsectores al PIB (gráfica 4), se encontró que el subsector de establecimientos financieros, seguros, actividades inmobiliarias y servicios a las empresas contribuyen al PIB en un $19.2 \%$ en promedio, siendo éste el subsector con mayor aporte dentro del sector servicios, teniendo, en general, un comportamiento uniforme en la década.

En seguida se encuentra el subsector asociado con servicios sociales, comunales y personales con una participación del $15.83 \%$ en promedio a lo largo de la década, siendo el segundo con mayor participación de los subsectores del sector terciario. El comercio aparece ubicado en tercer lugar con un aporte significativo al PIB de un $12 \%$ en promedio, como se pone en evidencia en la tabla 2. Esta cifra refleja la importancia de este subsector, no sólo en el sector de servicios sino además en toda la economía, debido a que permite la interrelación en los sectores productivos.

Con respecto al subsector de transporte, almacenamiento y comunicaciones, se puede decir que el desarrollo y sostenimiento de una economía dependen en gran medida de la capacidad de transportar, almacenar y tener una excelente infraestructura vial, 


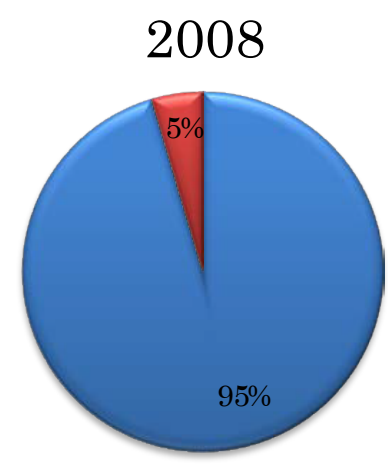

Exportaciones Totales

Exportacion sector servicios

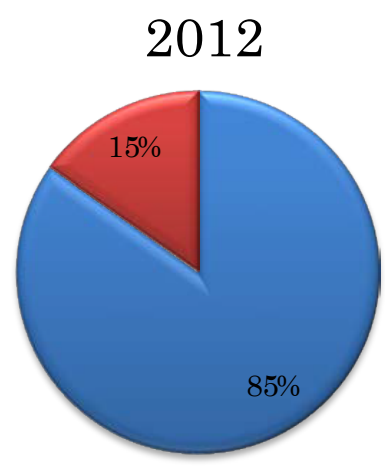

Exportaciones Totales

Exportacion sector servicios

Gráfica 5. Participación de las exportaciones del sector de servicios en el total de las exportaciones del país entre 2008 y 2012.

Fuente: elaboración propia a partir del DANE (2005, 2007, 2009, 2011, 2013).

sin dejar atrás la importancia de las comunicaciones como herramienta fundamental para el desarrollo; el aporte de este subsector al PIB fue en promedio del 7\% en la década.

Vale la pena mencionar que en Colombia la red vial se ha mantenido rezagada, convirtiéndose en una de las razones por la que en los planes de desarrollo se venga incluyendo la necesidad de mejorar y construir redes de carreteras, aeropuertos, puertos y vías fluviales que contribuyan al desarrollo de la economía por medio de la conexión de las diferentes regiones del país, y así, se contribuya a mejorar los aspectos relacionados con el comercio exterior.
Comercio exterior del sector de servicios, 2008-20124. Para observar el comportamiento de las exportaciones e importaciones del sector terciario en Colombia se estudiará el periodo 2008-2012 con la información registrada en el DANE y se analizará según agrupación $\mathrm{CABPS}^{5}$.

\footnotetext{
${ }^{4}$ En relación con el comercio exterior del sector de servicios, sólo se analiza en el periodo 2008-2012 debido a que no se registran datos para años anteriores.

${ }^{5}$ Los CABPS hacen referencia a la Clasificación Ampliada de la Balanza de pagos de servicios del país, donde se seleccionan las seis actividades de servicios más relevantes por sus características, las cuales son técnicamente viables a la hora de capturar la información a través de encuestas a empresas.
} 


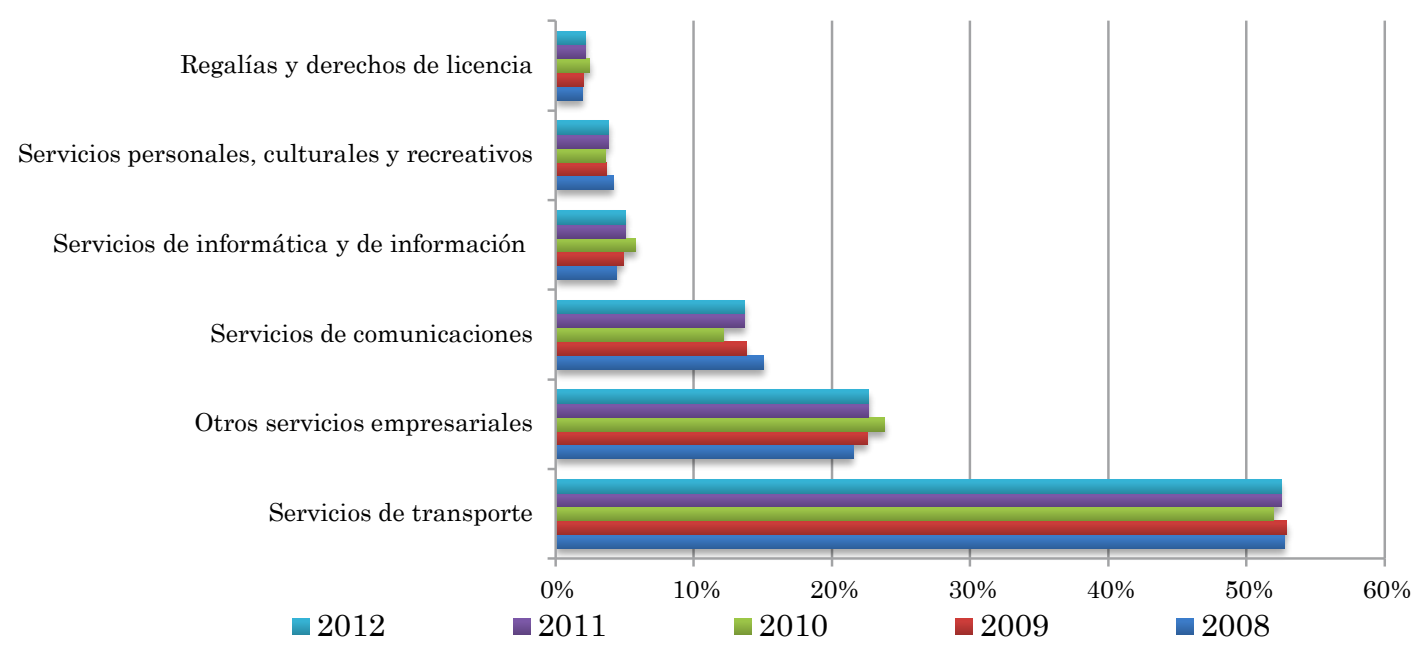

Gráfica 6. Exportaciones del sector de servicios.

Fuente: elaboración propia a partir del DANE (2005, 2007, 2009, 2011, 2013).

\section{Exportaciones del sector de servi-} cios en Colombia. La participación del sector de servicios en las exportaciones totales del país de 2008 a 2012 elevaron su participación, pasando de un $5 \%$ en 2000 a un $15 \%$ en 2012, demostrando no sólo la importancia del sector en el crecimiento económico del país sino también en la balanza comercial por sus contribuciones positivas.

Al interior del sector se encontró que del total de las exportaciones que se realizaron, el subsector de transporte fue el que mayor participación registró con 2.258.819 millones de dólares en prome- dio. Se debe resaltar que todos los subsectores tuvieron un comportamiento constante a través de los años analizados ya que las variaciones en exportaciones fueron mínimas, con excepciones como la de telecomunicaciones que en el año 2010 presentó una leve caída; así mismo, el subsector que menos exportó fue el de regalías y derechos de licencias, con un valor aproximado de 94.092 millones de dólares en promedio (gráfico 6).

Importaciones del sector de servicios en Colombia. La participación del sector de servicios en las importaciones totales del país disminuyó de 2008 a 2011, 


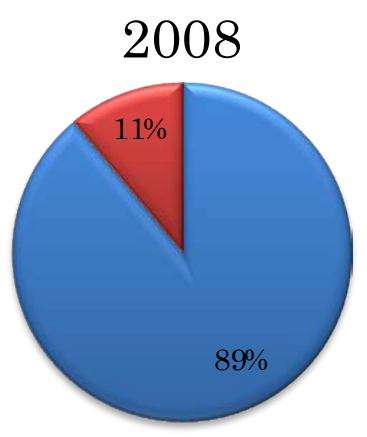

Importaciones Totales Importacion sector servicios

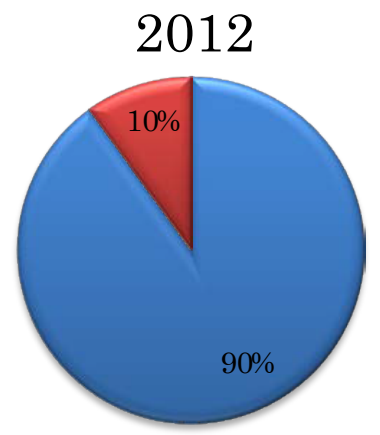

- Importaciones Totales

Gráfica 7. Participación de las importaciones del sector de servicios en el total. Fuente: elaboración propia a partir del DANE (2005, 2007, 2009, 2011, 2013).

pasando del $11 \%$ al $10 \%$, respectivamente. Esto demuestra el crecimiento del sector al interior del país, contribuyendo positivamente a la balanza comercial puesto que, como se mostró, las exportaciones nacionales han ido en ascenso a través de la década.

Al interior del sector se encontró que del total de las importaciones que se realizaron, el subsector de transporte fue el de mayor participación con 2.423.378 millones de dólares en promedio. Se debe resaltar que todos los subsectores tendieron a reducir sus importaciones a través de los años analizados, con excepciones como las de regalías y derechos de licencia, las cua- les se mantuvieron constantes, y otros servicios empresariales que han tendido a aumentar su participación, ya que pasaron de un $23 \%$ en 2008 a un $27 \%$ en 2012.

Al analizar el comportamiento de las exportaciones y de las importaciones, se encuentra que la balanza comercial ha venido mejorando con respecto al sector de servicios, ya que han disminuido las importaciones y aumentado las exportaciones, así mismo, el subsector de servicios de transporte se presenta como el más exportador y el más importador al mismo tiempo, convirtiéndose en el más importante al interior del sector. 


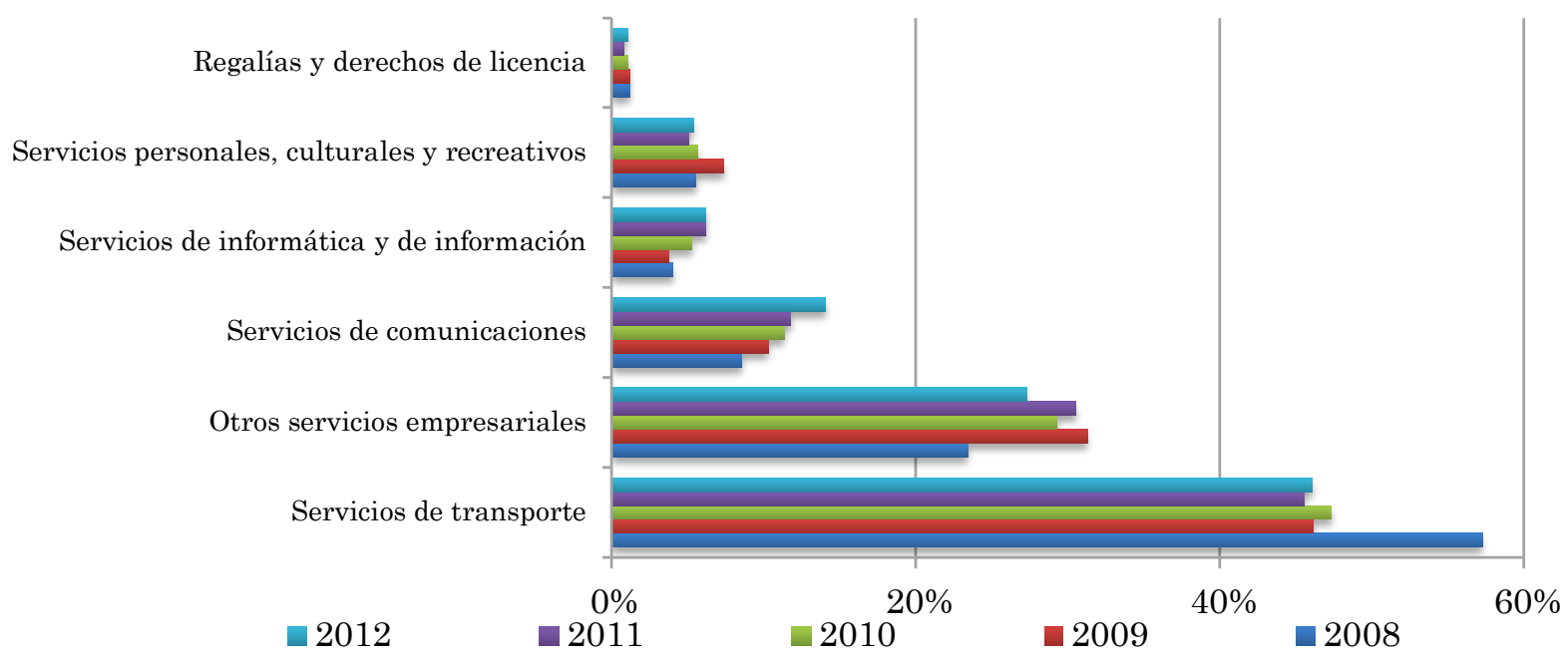

Gráfica 8. Importaciones del sector de servicios.

Fuente: elaboración propia a partir del DANE (2005, 2007, 2009, 2011, 2013).

\section{Participación del sector de servicios en el mercado laboral colombiano}

Como se pone en evidencia en el gráfico 14, el sector de servicios es el sector que más demanda mano de obra en la economía, con un 51\% aproximadamente, seguido por la industria manufacturera. Es evidente cómo ha cambiado el panorama, ya que para 1970 la agricultura y la industria eran las que predominaban en la esfera productiva del país, pero en la última década, el sector de servicios es el que ha venido registrando un mayor aporte y, por ende, ha aumentado la demanda de mano de obra (Fedesarrollo, 2013).
El sector de servicios demuestra su importancia en el mercado laboral al tener el 51\% del personal ocupado en la economía, lo que termina corroborando la importancia de este sector en la economía nacional, no sólo por las cifras positivas en los indicadores de crecimiento abordados, sino también por su alta participación en los niveles de empleo; esto proporciona una idea de hacia dónde se dirige el comportimiento de la economía y termina poniendo en evidencia la tercerización de la economía colombiana. Según Fedesarrollo (2013): 


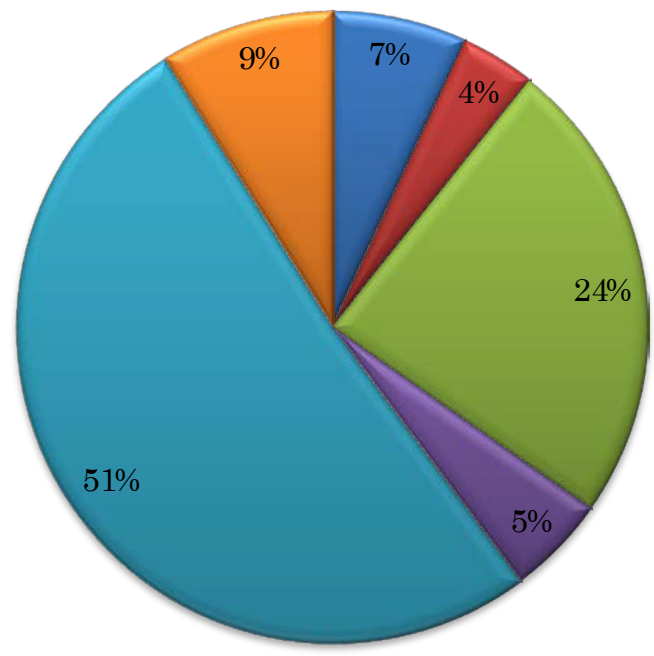

Agricultura.Ganadería.

Servicultura. Caza y Pesca

- Explotación de Minas y Canteras

- Industria Manufacturera

a Construcción

口ector Servicios

$\square$ Actividades no bien especificadas

Gráfica 9. Participación del sector de servicios en el mercado laboral.

Fuente: elaboración propia a partir del Min. Protección Social -Ministerio del Trabajo (Fedesarrollo, 2013).

"Durante la última década se generaron 4.8 millones de empleos en la economía colombiana. El comercio fue el sector que más ocupación creó al generar 1.5 millones de empleos, seguido por actividades inmobiliarias y servicios empresariales con 730 mil empleos y el sector de transporte y comunicaciones con 670 mil empleos".

\section{La innovación y el empleo en el sector de servicios en Colombia}

A continuación se desagrega la innovación presentada en el sector de servicios basados en los datos suministrados por la Encuesta de Desarrollo e Innovación Tecnológica en el Sector Servicios (EDITS), que permiten analizar de forma detallada el comportamiento de la innovación y el personal ocupado en ese sector, además, se presenta la relación entre estas variables para determinar la incidencia del empleo en los procesos innovativos del sector de servicios.

Entre los indicadores simples se encuentran: la participación según el tipo de innovación en el sector de los servicios, la innovación de producto en el sector de servicios, la innovación de procesos en el sector de servicios, las innovaciones organizativas 
del sector de servicios, las innovaciones de mercadotecnia en el sector de servicios, el personal ocupado por nivel educativo en el sector de servicios, personal ocupado con posgrados en el sector de servicios, profesionales ocupados en el sector de servicios, técnicos y tecnólogos ocupados en el sector de servicios, el personal ocupado con primaria y/o secundaria en el sector de servicios, los trabajadores calificados ocupados en el sector de servicios y otros trabajadores ocupados en el sector de servicios.

Analizando la innovación en el periodo estudiado se encontró que la innovación de procesos es la que más aporta a las activi- dades de innovación, con un $46 \%$ en el total de las innovaciones presentadas en el periodo estudiado, registrando su mayor aporte en el periodo 2008-2009 con un 49\% de las innovaciones presentadas. En segundo lugar se encuentra la innovación de producto con un $28 \%$ de las innovaciones totales, teniendo su mayor aporte en el periodo 20082009 con un 59\% de participación.

\section{Personal ocupado por nivel educa-} tivo en el sector de servicios. El personal ocupado de las empresas se clasifica en nueve grupos según el nivel educativo, donde están: doctorado y maestría, especialización, profesional, tecnólogo, técnico,

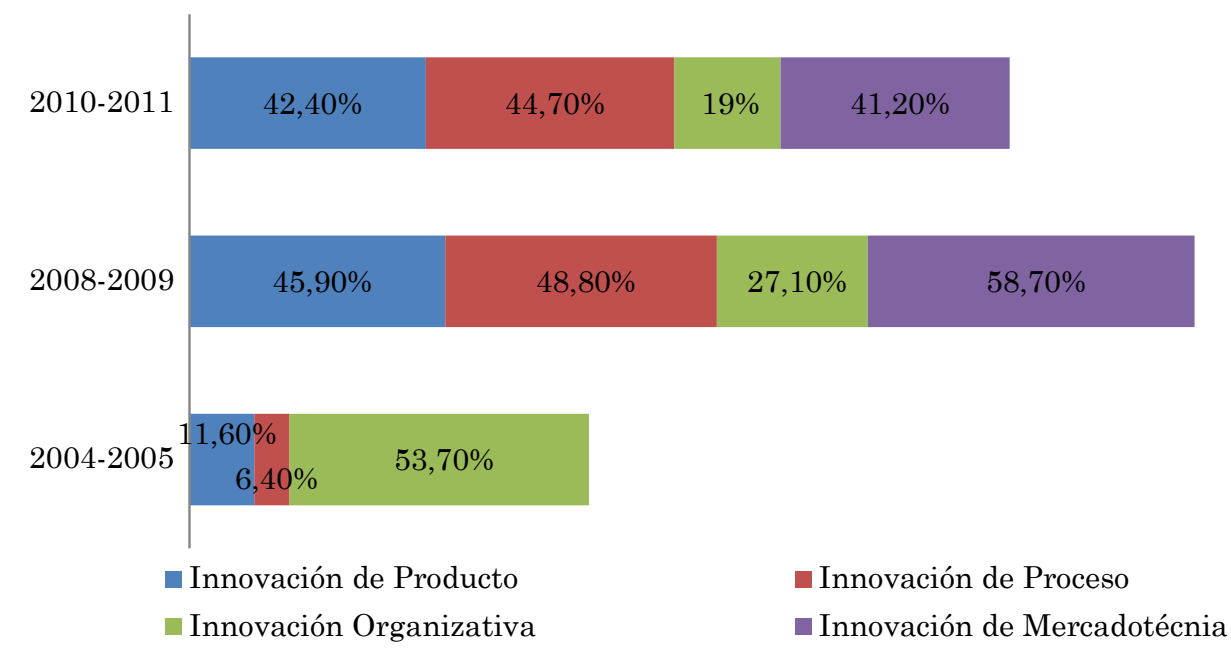

Gráfico 10. Participación según el tipo de innovación en el sector de servicios.

Fuente: elaboración propia a partir del DANE-EDIT (2005, 2007, 2009, 2011, 2013). 
Tabla 2

Clasificación del personal ocupado.

\begin{tabular}{|c|c|c|c|c|c|c|c|c|}
\hline $\begin{array}{l}\text { Doctorado } \\
\text { y maestría }\end{array}$ & Especialización & Profesional & Tecnólogo & Técnico & $\begin{array}{c}\text { Educación } \\
\text { secundaria }\end{array}$ & $\begin{array}{c}\text { Educación } \\
\text { primaria }\end{array}$ & $\begin{array}{c}\text { Trabajadores } \\
\text { calificados }\end{array}$ & Otros \\
\hline & sgrados & Profesional & Técnico/t & ecnólogo & Secundari & /primaria & $\begin{array}{c}\text { Trabajadores } \\
\text { calificados }\end{array}$ & Otros \\
\hline
\end{tabular}

Fuente: elaboración propia a partir DANE-EDIT (2005, 2007, 2009, 2011, 2013).

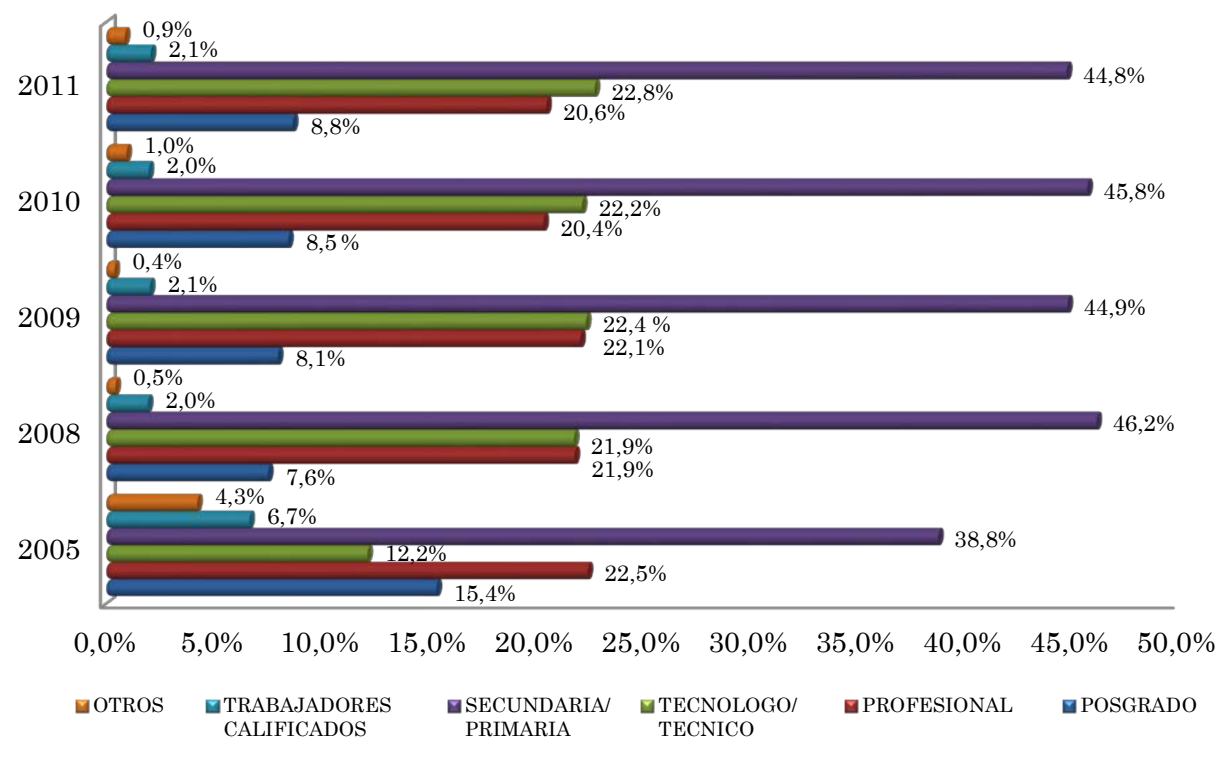

Gráfica 11. Personal ocupado por nivel educativo en el sector servicios.

Fuente: elaboración propia a partir del DANE-EDIT (2005, 2007, 2009, 2011, 2013).

educación secundaria, educación primaria, trabajadores calificados ${ }^{6}$ y otros. Para faci-

\footnotetext{
${ }_{6}$ Trabajadores calificados agrupa al personal ocupado que a pesar de no tener ninguna clase de estudios formales poseen algún registro calificado requerido para desempeñarse en una actividad específica.
}

litar el análisis, se redujo la clasificación a seis grupos donde se agrupan doctorado, maestría y especialización en posgrados; técnico y tecnólogo en técnico/tecnólogo; y educación secundaria y educción primaria en secundaria/primaria. 
Del total del personal ocupado en 2005, siendo éste de 651.432, el personal que mayor participación tuvo fue el de secundaria y primaria, con un $38 \%$, seguido de profesionales, con un $22 \%$, mientras que otro tipo de personal ocupó el 4\%. Para el 2008, el personal ocupado aumentó en un 7\% siendo de 695.581. En este periodo el personal con secundaria/primaria incrementó su participación, siendo ésta de un $46 \%$, mientras que otro tipo de personal ocupado disminuyó su participación, registrando un $0,5 \%$.
En 2009 continuó aumentando el número de personal ocupado, siendo éste de 723.622, representando un incremento del $4 \%$ con respecto al año anterior. El personal con secundaria/primaria continuó como el que mayor participación tuvo con un 44\%, y el que menor participación tuvo fue el de otra clase de personal con un $0,5 \%$.

En 2010 se vio un incremento considerable de la población ocupada, siendo ésta de 945.009 y registrando un incremento

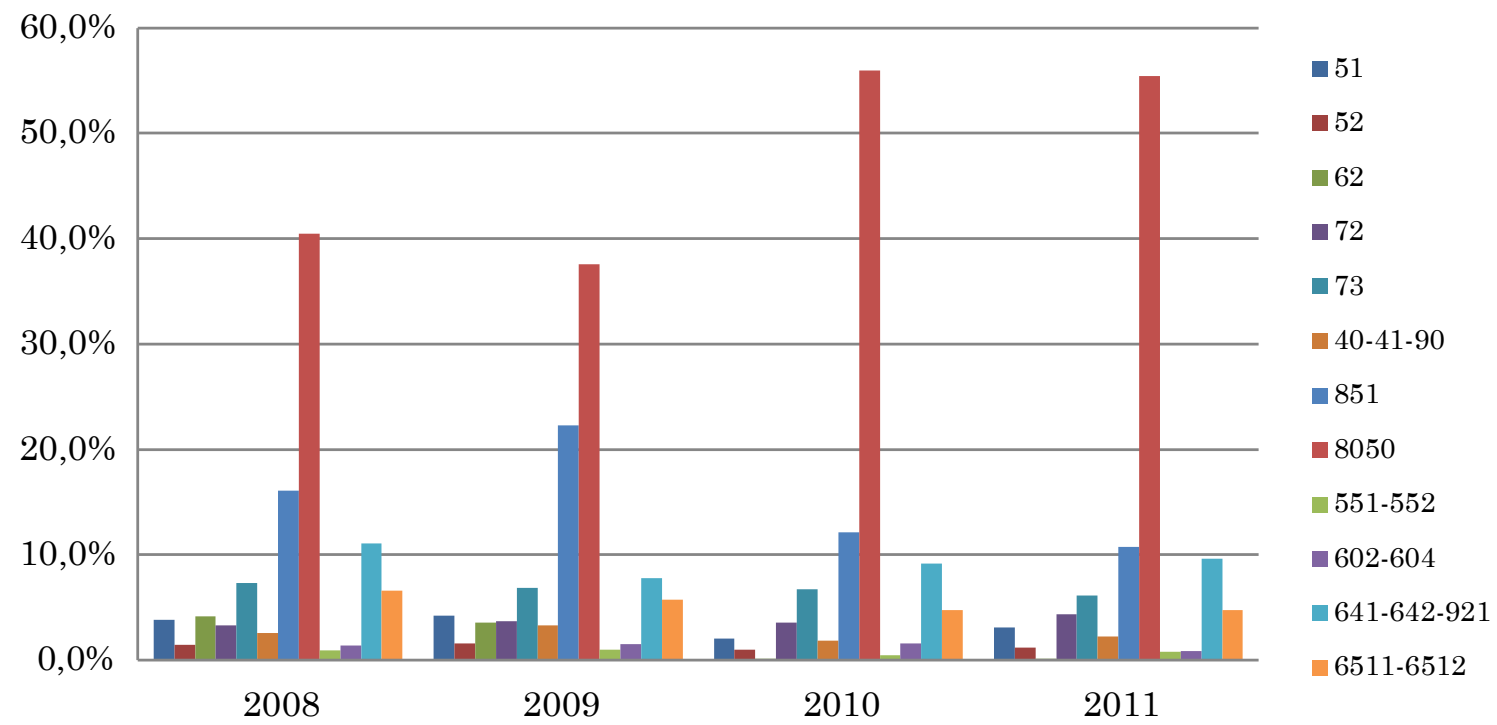

Gráfico 12. Personal con posgrado que participó en ACTI en el sector de servicios.

Fuente: elaboración propia a partir del DANE-EDIT $(2005,2007,2009,2011,2013)$. 
del $31 \%$ con respecto al 2009. Al igual que en los anteriores años, el personal con secundaria/primaria tuvo la mayor participación, con un $46 \%$, y la categoría que tuvo una menor participación fue el de otro personal ocupado con un $0,9 \%$.

En 2011 incrementó el personal ocupado en un $6 \%$ con respecto a 2010 , siendo de 998.245 personas. En este año se mantuvo la tendencia del periodo en general donde el personal ocupado con mayor participación fue el secundaria/ primaria con un $44 \%$ y otro personal ocupado, con un $0,9 \%$, fue el de menos participación.
Personal ocupado en Actividades de Ciencia, Tecnología e Innovación (ACTI) en el sector de servicios. $\mathrm{Al}$ analizar el personal ocupado en ACTI, se observa que para el año 2005 no se registraron datos relacionados, por lo que el análisis se abordó a partir del año 2008. En general, el personal ocupado profesional fue el que más participó en ACTI en el periodo, con su máxima participación en el año 2010 con un $38 \%$, seguido por posgrados con su mayor participación en 2011 con un $32 \%$; el menor aporte lo registró otros con un $0.3 \%$ en promedio. Los tecnólogos/técnicos mantuvieron un comportamiento estable en el periodo con una participación del $20 \%$ en promedio.

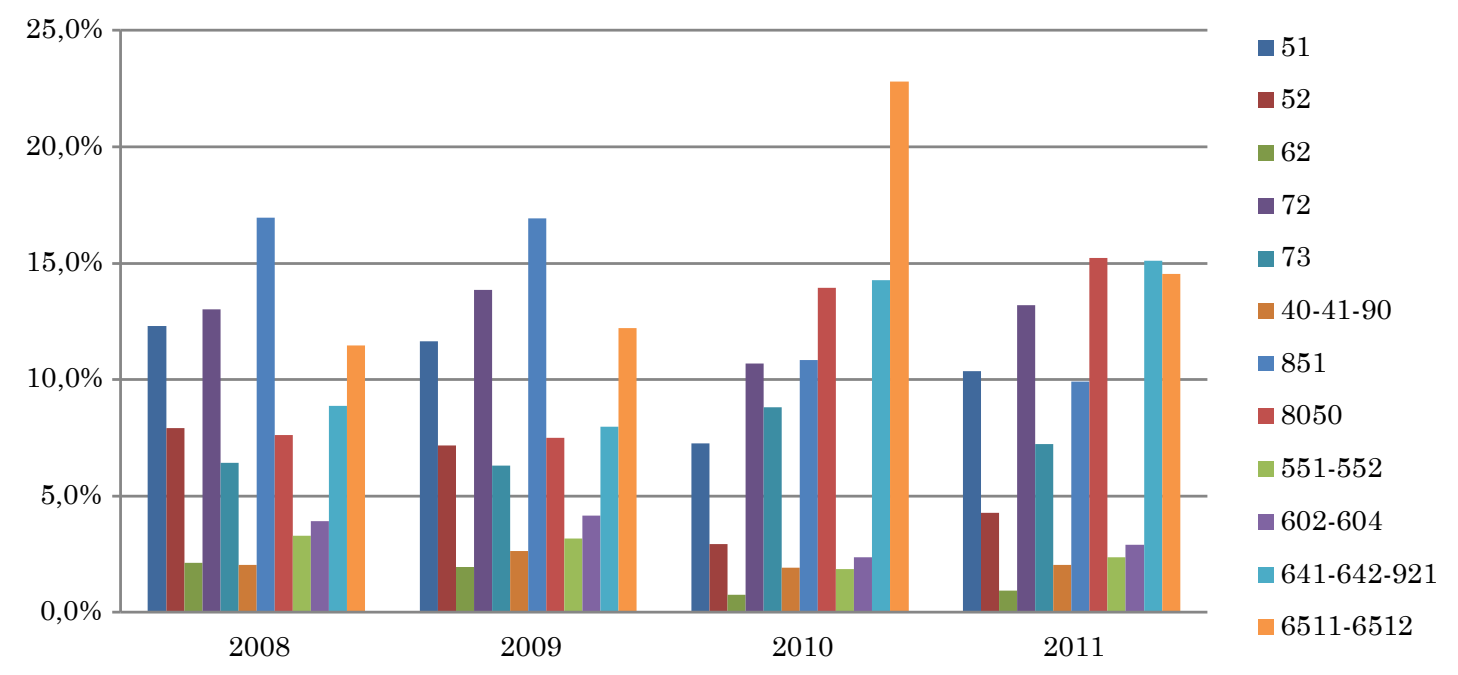

Gráfico 13. Profesionales que participaron en ACTI en el sector de servicios. Fuente: elaboración propia a partir del DANE-EDIT (2005, 2007, 2009, 2011, 2013). 
El personal con posgrados que participó en ACTI tuvo su mayor participación en el subsector de educación superior, siendo ésta en promedio de un $12 \%$, y teniendo su mayor registro en 2011 con un 30\%. Es importante ver cómo se incrementó su participación, ya que en 2005 era del $21 \%$, lo que registra un $9 \%$ de aumento en los periodos subsiguientes. En la actividad que menos se implementó personal con posgrados fue en la de hoteles y restaurantes.

Con respecto al personal profesional, se observa que su mayor participación se encuentra en actividades relacionadas con la salud humana, teniendo su mayor aporte en 2009 con un 4,5\%. En el año 2011, esta actividad es desplazada por educación superior privada en cuanto a personal profesional ocupado, ya que registra un $4,1 \%$ superando a las actividades relacionas con la salud humana en un 1,4\%. La actividad que menos personal profesional requirió fue la de servicios públicos domiciliarios, teniendo en promedio un $0,5 \%$ de personal profesional dedicado a ACTI.

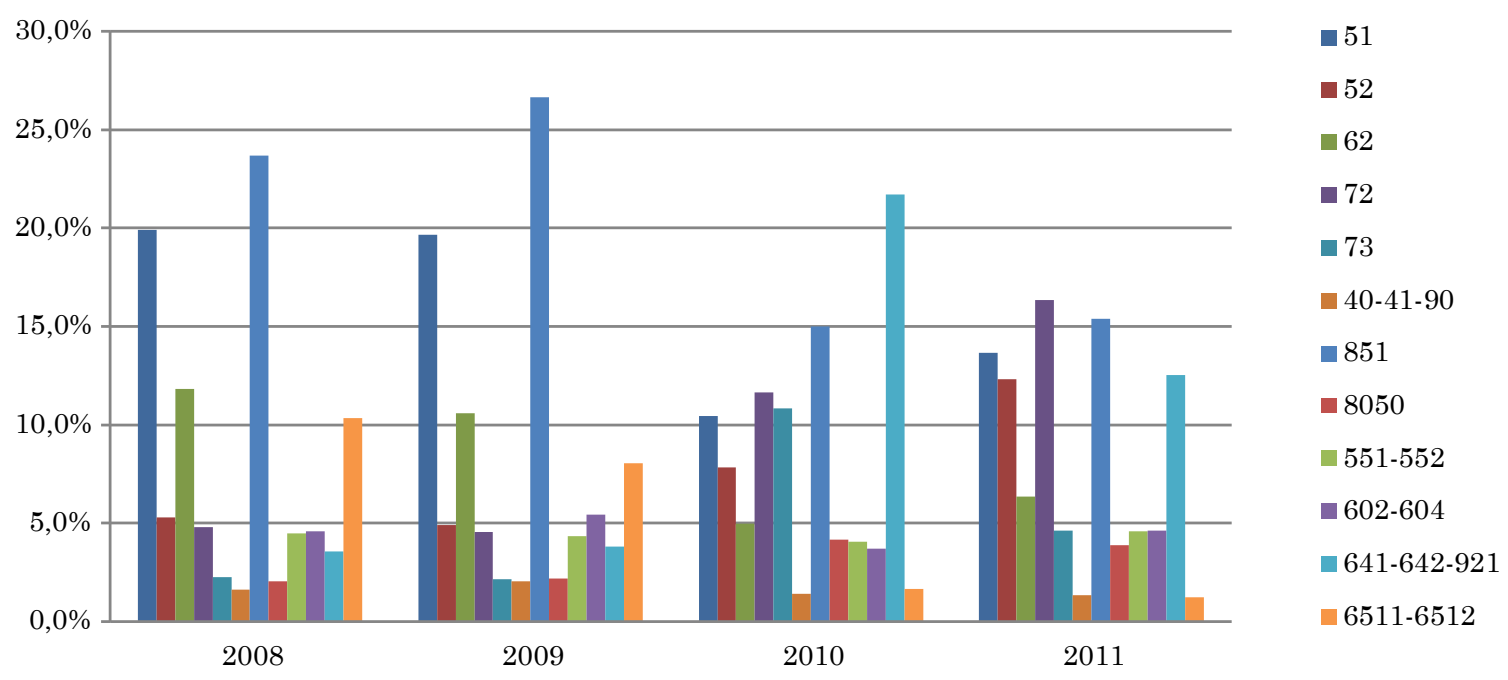

Gráfico 14. Técnicos/tecnólogos que participaron en ACTI en el sector de servicios.

Fuente: elaboración propia a partir del DANE-EDIT $(2005,2007,2009,2011,2013)$. 
El subsector de actividades relacionadas con la salud humana es el que más profesional técnico/tecnólogo ha requerido, siendo en promedio de un 5,2\%, mientras que la actividad que menos profesional técnico/tecnólogo ocupó en ACTI fue la de servicios públicos domiciliarios con un $0,4 \%$ en promedio. La participación de personal técnico/ tecnólogo en ACTI ha venido disminuyendo, ya que pasó del $27 \%$ en 2008 a un $22 \%$ en 2011.

Las actividades relacionadas con comercio al por menor excepto vehículos automotores y combustibles, en 2008 y 2009 , constituyeron el subsector que ocupó mayor personal con secundaria/primaria en ACTI, siendo de un $16 \%$ en promedio; mientras que, para 2010 y 2011, el sector con mayor participación de este tipo de personal fue el de transporte de pasajeros por vía terrestre y de carga por carretera. En el periodo de análisis, el personal con secundaria/primaria ha venido disminuyendo su participación en ACTI, ya que en 2008 registraba el 35\% y en 2011 registró un $15 \%$.

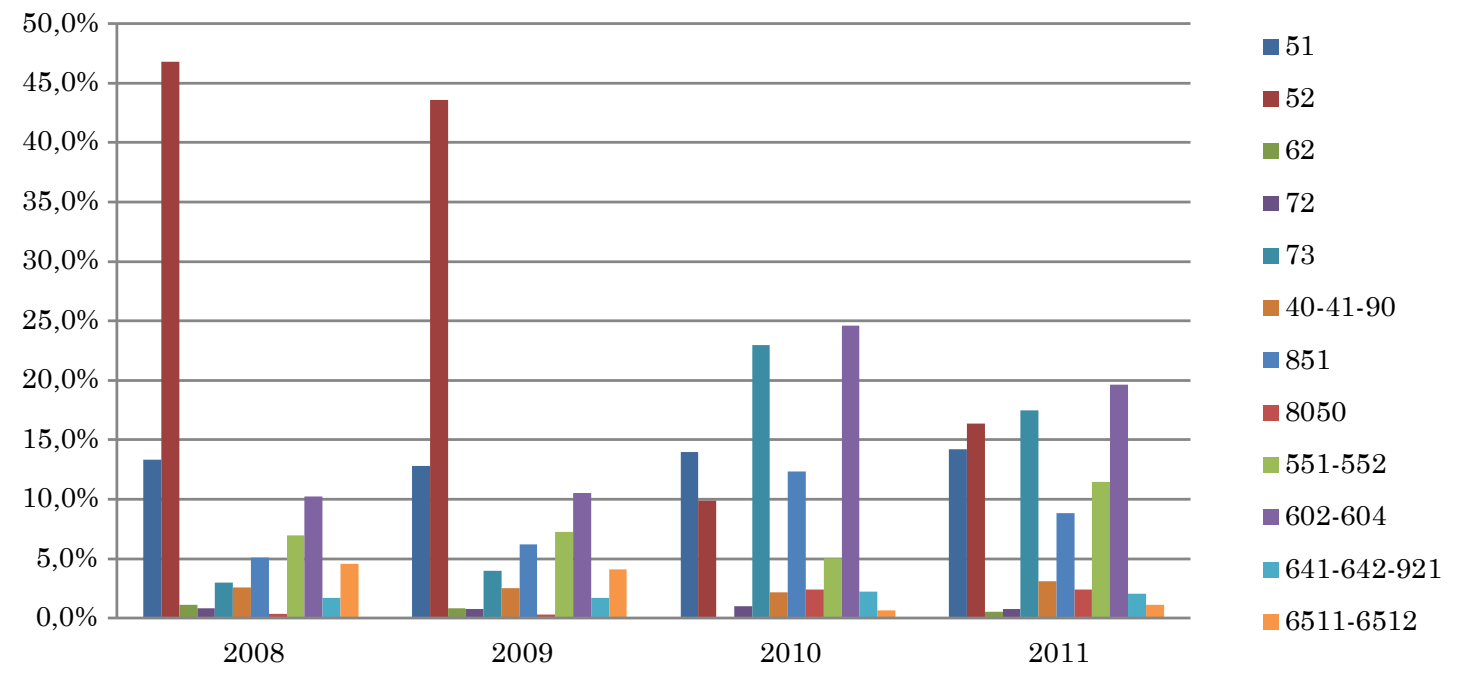

Gráfico 15. Personal con secundaria que participó en ACTI en el sector de servicios.

Fuente: elaboración propia a partir del DANE-EDIT (2005, 2007, 2009, 2011, 2013). 


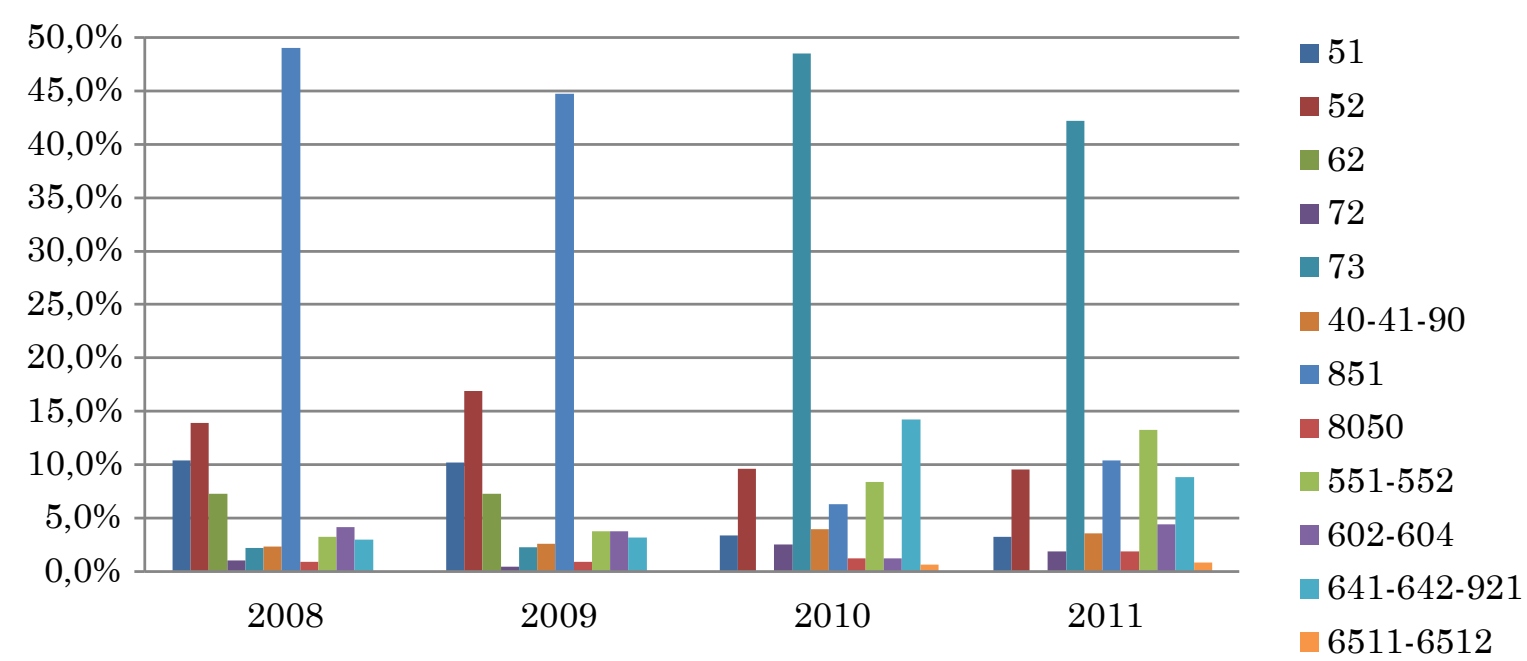

Gráfico 16. Trabajadores calificados que participaron en ACTI en el sector de servicios. Fuente: elaboración propia a partir del DANE-EDIT (2005, 2007, 2009, 2011, 2013).

En 2008 y 2009 , los trabajadores calificados dedicados a ACTI tuvieron su mayor participación en actividades relacionadas con la salud humana, teniendo un $14 \%$ en promedio. Para 2010-2011 consiguieron su mayor registro con centro de investigación y desarrollo, siendo éste en promedio de un $8 \%$. Las actividades bancarias fueron las que menos trabajadores calificados ocuparon, siendo en promedio del 0,1\%. Los trabajadores calificados a lo largo del periodo analizado han venido disminuyendo su participación, ya que pasaron de un $28 \%$ en 2008 a un $21 \%$ en 2011.
Con referencia al personal ocupado con otras especificaciones dedicados a ACTI, se ve cómo existen sectores en los que no se registra ocupación, como lo son los subsectores de actividades bancarias; correos y telecomunicaciones; educación superior privada; e informática y transporte por vía aérea. En el año 2008 este tipo de personal ocupado tuvo su mayor participación y estuvo ubicando en el subsector hoteles y restaurantes, con un aporte del $12,5 \%$ en su mejor registro. 


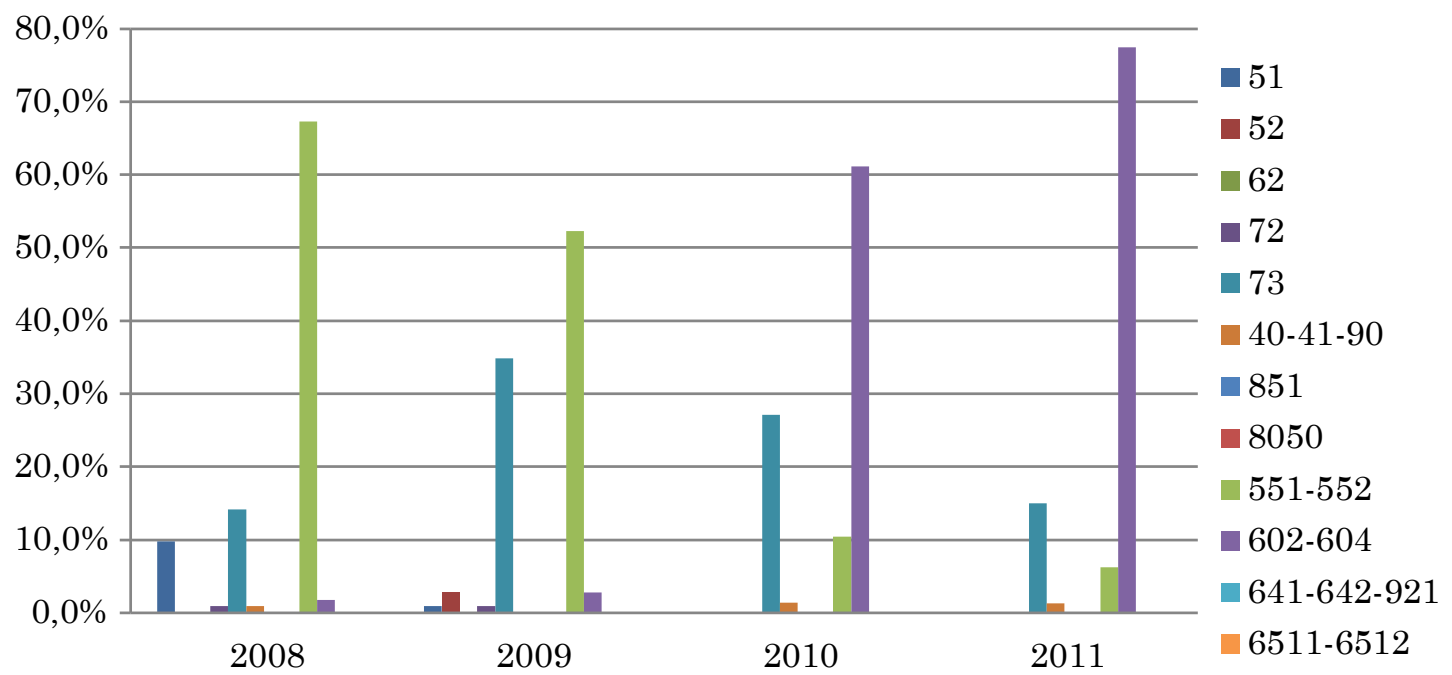

Gráfica 17. Otro personal que participó en ACTI en el sector de servicios. Fuente: elaboración propia a partir del DANE-EDIT (2005, 2007, 2009, 2011, 2013).

En general, el personal el ocupado del sector de servicios ha venido incrementando su participación, ya que pasó de 648.340 a 998.225 personas ocupadas con una tasa de crecimiento promedio del $12 \%$ anual en el periodo de estudio, donde del año 2009 al 2010 el personal ocupado registró un incremento del $32 \%$.

El personal ocupado en ACTI representó un $4 \%$ del total del personal ocupado en el sector de servicios, donde el personal profesional tuvo una participación del $34 \%$, seguido por el personal con posgrados y un
$27 \%$ de la participación. La actividad que registró la mayor participación de personal fue la relacionada con la salud humana con un $4,1 \%$ en promedio en el 2008 2009, y actividades bancarias registró un $4,8 \%$ en promedio en 2010-2011.

\section{Relación del personal ocupado en ACTI con la innovación en el sector} de servicios. Al analizar el personal ocupado en ACTI con respecto a la innovación total del sector de servicios, se encontró cómo éste disminuyó su participación en un $23 \%$ de 2008 a 2010 . Igualmente, las in- 
novaciones presentadas en ese periodo disminuyeron un $13 \%$. Por esta razón, a primera vista se puede percibir una relación directa entre las dos variables al presentar el mismo comportamiento. Cuando se analiza en profundidad el comportamiento de cada una de las variables, se encuentra que la disminución en el personal ocupado en ACTI no refleja un impacto significativo en la reducción de innovaciones, ya que a pesar de la tendencia a la disminución en las dos variables, el personal ocupado presenta una mayor reducción en comparación con las innovaciones presentadas, por lo tanto, no se puede afirmar que la relación existente sea directa, ya que no precisa el grado de influencia entre las dos variables; además, se señala que el personal ocupado en ACTI en el sector servicios tan sólo representa un $4 \%$ del total del personal del sector, lo que afianza la idea de que el personal no tiene una relación significativa con la innovación del sector.

Relación del personal ocupado ${ }^{7}$ en ACTI por nivel educativo con la innovación en el sector de servicios. El personal ocupado con posgrado en ACTI en el sector servicios refleja un incremento en el periodo analizado, pasando de

${ }^{7}$ Se analizaran el periodo $2008-2009$ y 2010-2011 ya que no se registran datos del personal ocupado en ACTI para el periodo 2004-2005.
8.555 en 2008 a 12.790 personas en 2011 , creciendo un $14 \%$ en promedio y teniendo una participación del $27 \%$ en el total de personal ocupado en ACTI, mientras que la innovación total disminuyó un 13\%. El subsector que más personal con posgrados ocupó fue el de educación superior privada, donde el tipo de innovación que más se presentó fue la innovación de producto con una participación del $44 \%$ en las innovaciones del subsector. Lo anteriormente dicho indica que el personal ocupado con posgrados no tiene un impacto en las innovaciones presentadas, debido a que mientras éste va en aumento, las innovaciones tienen un comportamiento inverso, disminuyendo el número de innovaciones presentadas.

Los profesionales representan el 34\% del personal ocupado en ACTI en el sector de servicios, los cuales presentaron un incremento del $34 \%$ en promedio, pasando de 11.827 a 14.619 profesionales ocupados, donde la mayoría se ubicaron en el subsector de actividades bancarias y donde el tipo de innovación más usado fue el de la innovación de producto con una participación del $49 \%$ en las innovaciones totales. Al igual que el personal con posgrados, los profesionales no tienen un impacto significativo en las innovaciones puesto que ambas variables presentan comportamientos opuestos. 
Los tecnólogos y técnicos ocupados en ACTI en el sector de servicios participan en un $21 \%$, presentando una disminución del $20 \%$ en promedio en el periodo estudiado, pasando de 9.108 a 7.440 tecnólogos y técnicos ocupados. El subsector en el que mayor participación se registró fue en actividades relacionadas con la salud humana, donde la innovación en procesos fue la más representativa, siendo ésta de un $46 \%$ del total de las innovaciones presentadas en este subsector.

En cuanto a personal ocupado con primaria y/o secundaria, personal calificado y otros, la participación en ACTI fue de $18,4 \%$ del total del personal ocupado en ACTI, donde se registra una disminución del $46 \%$ de participación en el periodo estudiado, pasando de 10.141 a 4.736 ocupados, donde los centros de investigación y desarrollo son los que requieren menos de esta clase de personal.

Si bien en los dos últimos grupo analizados las variables reflejan el mismo comportamiento, en donde tanto el personal ocupado como la innovación disminuyen año tras año, no se puede aseverar que tengan una relación directa, ni mucho menos que generen un impacto sobre la innovación del sector, debido a que los anteriores análisis nos demuestran lo contrario.

\section{Conclusiones}

El sector de servicios en Colombia ha venido ganando gran importancia en la economía debido a su creciente participación en el Producto Interno Bruto (PIB), tal como se evidencia en la última década, siendo ésta de casi del 64\%. Sin embargo, esta no sólo se puede limitar a su aporte al PIB, también por la cantidad de personal ocupado que participa en este sector, siendo del 51\% aproximadamente, asimismo, por el aumento en las exportaciones de este sector, las cuales pasaron de un 5\% en 2008 a un $15 \%$ en 2012 y, además, por la disminución en las importaciones, las cuales pasaron de un $11 \%$ en 2008 a un $10 \%$ en 2012. Es importante resaltar que dentro del sector servicios, los subsectores con mayor participación son los de establecimientos financieros y servicios sociales y comunales con una participación del 34\% y $26 \%$ para 2012 , respectivamente.

En el periodo estudiado se encontró que tanto la innovación como el personal ocupado en ACTI han venido disminuyendo año tras año de manera general, presentando su mayor descenso en 2010 cuando el personal ocupado registró una disminución del $23 \%$ y la innovación del 13\%, manteniéndose esta tendencia en los cuatro tipos de innovación y en el personal ocupado pertenecientes a los grupos tecnólogos/ 
técnicos, primaria/secundaria, calificados y otros. Aunque el personal ocupado de los grupos posgrados y profesionales sí presentaron un incremento en la participación ACTI, esto no influyó en el crecimiento de la innovación.

Con respecto a los tipos de innovación, las cuatro (innovación de producto, proceso, organizativa y mercadotecnia) presentaron el mismo comportamiento, teniendo un crecimiento significativo (227\%) del primer periodo al segundo periodo ${ }^{8}$, para, posteriormente, disminuir en un $13 \%$. La innovación más representativa fue la innovación de proceso con un $46 \%$, seguida de la innovación de producto con un $28 \%$ y, en último lugar, se encuentra la innovación organizativa con un $26 \%$ de participación (incluyendo la innovación de mercadotecnia).

El subsector con más innovaciones de proceso fue comercio al por mayor excepto el comercio de vehículos y combustibles, donde se realizaron 3.278 innovaciones de proceso, representado el $32 \%$ del total de las innovaciones hechas en dicho subsector; el personal ocupado fue de 139.517 de los cuales 16.227 se dedicaron a ACTI, re-

\footnotetext{
${ }^{8}$ El primer periodo de análisis empieza en los años 20042005 y va hasta los años 2008-2009, y el segundo periodo de análisis va desde los años 2008-2009 hasta 2010-2011.
}

presentando el 11\%, lo que refleja una baja participación del personal en ACTI y que el personal ocupado no muestra un impacto en la innovación del sector.

El personal ocupado en el sector servicios aumentó considerablemente en el periodo estudiado, pasando de un 648.340 en 2005 a 998.245 en 2011, presentando un crecimiento del 54\%; contrario a esto, el personal ocupado en ACTI en el sector servicios tuvo un comportamiento inestable, registrando en general una disminución del personal ocupado en ACTI del 0,1\%, donde su mejor año fue 2009 con 45.759 ocupados, disminuyendo posteriormente hasta su último registro en 2011 con 39.585 ocupados.

El subsector más innovador del sector de servicios fue comercio al por mayor excepto comercio de vehículos y combustibles, con 10.077 innovaciones equivalentes al $20 \%$ de las innovaciones totales presentadas en el sector, donde un 22\% (1.532) fueron innovaciones de producto, un 47\% (3.278) innovaciones de proceso y un $31 \%$ (2.214) innovaciones organizativas y de mercadotecnia. El personal ocupado en ACTI en este subsector fue de 4.513, equivalentes al $10 \%$ del total del personal ocupado en ACTI en el sector de servicios, apareciendo los profesionales en primer lugar con un 36\%, seguido por los técnicos y tecnólogos con un $35 \%$ al interior de subsector. 
Con 770 innovaciones equivalentes al $2 \%$ de las innovaciones totales, el subsector de transporte por vía aérea se convierte en el menos innovador del sector de servicios, ocupando 4.810 personas, tan sólo el 3\% del total de ocupados en ACTI del sector.

El subsector que más personal ocupó en ACTI fue el de educación superior con 28.129 ocupados equivalentes al $18 \%$ del total de personal ocupado en el sector, donde el personal con mayor participación fue el de posgrados con un 74\%. La innovación más presentada fue la de producto con 1.491 innovaciones, representando el $47 \%$ de las innovaciones totales.

Por otro lado, el subsector que ocupó menos personal en ACTI en el periodo fue el de servicios públicos domiciliarios, ocupando el $2 \%$ del total del personal y el noveno lugar en las innovaciones totales, aportando un $6 \%$ equivalente a 3.325 innovaciones, lo que a manera de comparación con el subsector más innovador (comercio al por mayor excepto comercio de vehículos y combustibles) representa tan sólo las innovaciones presentadas en proceso.

Aunque la evidencia empírica nos muestra que tanto la innovación como el personal ocupado en ACTI en el sector de servicios colombiano han venido disminuyendo, no se puede dejar atrás la falta de homogeneidad de las técnicas de medición en los procesos innovativos en el periodo analizado, ya que esta disminución puede estar atribuida a los cambios en la metodología que permitieron hacer más precisos los cálculos y disminuir el porcentaje de error.

\section{Referencias}

DANE. (2005). Encuesta de Desarrollo e Innovación Tecnológica en el Sector Servicios - EDIT - II 2003 - 2004. [En línea]. Recuperado de: https://www. dane.gov.co/files/investigaciones/industria/innovacion_tecnol_ind_manufacturera.pdf

DANE. (2007). Encuesta de Desarrollo e Innovación Tecnológica en el Sector Servicios - EDIT - III 2005 - 2006. [En línea]. Recuperado de: https:// www.dane.gov.co/files/investigaciones/boletines/edit/boletin_EDIT_Manufacturera.pdf

DANE. (2009). Encuesta de Desarrollo e Innovación Tecnológica en el Sector Servicios - EDIT - IV 2007 - 2008. [En línea]. Recuperado de: https:// formularios.dane.gov.co/Anda_4_1/ index.php/catalog/rdf/19 
DANE. (2011). Encuesta de Desarrollo e Innovación Tecnológica en el Sector Servicios - EDIT - V 2009 - 2010. [En línea]. Recuperado de: https://formularios.dane.gov. co/Anda_4_1/index.php/catalog/rdf/218

DANE. (2013). Encuesta de Desarrollo e Innovación Tecnológica en el Sector Servicios - EDIT - VI 2011 - 2012. [En línea]. Recuperado de: https://www.dane.gov.co/ files/investigaciones/boletines/edit/boletin_EDIT_Manufacturera_2011_2012. pdf

Fedesarrollo. (2013). Composición sectorial del empleo en Colombia. Bogota: ACRIP. [En línea]. Recuperado de: http:// www.fedesarrollo.org.co/wp-content/ uploads/2013/05/IML-Febrero.pdf
ISEA. (2008). Análisis prospectivo sobre modelos de innovación en el sector servicios. España: Ministerio de Industria, Turismo y Comercio.

OCDE y EUROSTAT. (1992). Manual de Oslo. Guía para la recogida e interpretación de datos sobre innovación. [En línea]. Recuperado de: http:// www.dgi.ubiobio.cl/dgi/wp-content/ uploads/2010/07/manualdeoslo.pdf

Schumpeter, J. (1997). La Teoría del Desenvolvimiento Económico. México D.F.: Fondo de Cultura Económica. 